every other respect, had put on flesh rapidly, and was happy and more like his old self. However, this spot grew with astounding rapidity, and on the' I Ith January I was called to put an end to the dog's suffering, as the tumour was now twice as large as it had ever been and was sloughing. The dog had wasted as rapidly as the tumour had grown and was a mere skeleton, with scarcely enough strength to crawl about. At the particular request of the owner I made no postmortem examination, so that I am unable to furnish any information as to the presence or absence of metastatic growths.

The accompanying figure shows the histology of the recurrent growth $(\times 57)$.

\title{
A CASE OF CEREBRO-SPINAL MENINGITIS.
}

By the Same.

FROM the information I can gather from various works on pathology, and on that of the dog in particular, this disease appears to be considered rare in the dog. From my own observation I have come to the conclusion that spinal meningitis in various forms is common, and not infrequently complicated with cerebral symptoms. Cerebro-spinal meningitis occurring as an epidemic I have not seen.

The leading characteristics of spinal meningitis are hyperæsthesia and paralysis or paresis, without disturbance of consciousness or of the higher functions. Where the cerebral meninges are affected consciousness is impaired, though there is also incoordination of movement and paralysis generally supervenes. All these characteristics were well shown in the following case :-

The patient'was a young blue Pomeranian (male), aged about ten months, weight about $5 \mathrm{lbs}$., and in apparently good health up to the time of the onset of the disease. Two or three months previously the puppy had distemper in a mild form, that is to say, there had been a characteristic primary and secondary eruption on the skin and a slight husky cough, but practically no nasal or conjunctival catarrh. He was brought to me one afternoon with the history that he seemed uneasy and excitable. I noticed that the dog was far more nervous than usual and cried out if any sudden movement was made towards him, which had not been his usual custom; put on the ground, he walked unsteadily, though it was impossible to say that there was any loss of locomotive power in any particular limb. He was by no means dazed, the pupils of both eyes were evenly dilated, and there was no apparent pain to be located anywhere about the body. The muscles of the neck were perhaps a trifle harder and more prominent than normal, though not noticeably so. Temperature was $1^{\circ}$ above normal.

I made no diagnosis at this examination, preferring to wait till the next day, and meanwhile trying if possible to exclude the possibility of reflex.nervous irritation from foreign bodies or worms in the intestine. I thereupon prescribed 3 grs. santonin and 2 grs. calomel.

Next morning (second day of illness) I saw him again. There had been no result from the powder beyond two very loose motions. The dog's condition was, however, much more acute. His neck was now deflected to the right, the head being turned slightly to the left, giving him a peculiar wry-necked appearance. The right pupil was slightly 
more dilated than the left; the muscles of the neck were tense and acutely sensitive, as were also his ears and jaws. His back was arched, he crossed his fore legs in walking, and there was a tendency to turn to the left. He seemed perfectly conscious and ate some meat readily, though he had been twice sick during the morning. I now prescribed santonin, 3 grs., and calomel, 2 grs., in the morning, followed by grey powder, 3 grs., at night.

On the third day the illness reached its most acute stage. The dog during the morning was roused almost to frenzy by the sound of the piano, which was being played in an adjoining room, but became quiet at once on the sound ceasing. The singing of a canary affected him almost in the same way. If one whistled in the same room with him he would scream and rush round the room, jumping up at the walls as if mad. His owner was confident that he was mad. I found him lying in his basket semi-conscious, in fact, semi-comatose, though noise or handling would rouse him, when he would scream loudly. He had passed one worm (ascaris) during the night. All the same symptoms noticed on the previous day were present, only all in a more aggravated form. The pupil of the right eye was widely dilated, that of the left contracted, and both eyes showed a slight blue film, the left being more noticeable. The head was slightly rotated to the right, the whole body and limbs acutely sensitive. His temperature could not be taken owing to his extreme nervousness. I had him put in a darkened room and continued the medicines as before. I did this as I thought the mercury would be the best means of causing free purgation in such a young dog, especially as I now had cause to fear his condition being aggravated by reflex irritation.

The fourth morning brought a slight improvement. The patient was not quite conscious and had scarcely moved for twelve hours. There had been no more frenzy, but he had been fully purged and had passed one or two more worms. The neck was not quite so hard or so painful, but he seemed unable to control his movements, knocking against furniture and falling over it if left to himself, so he was shut up in a wicker cage.

On the fifth day he was perfectly conscious, but was partially paralysed in the right fore leg and in both hind limbs; his tail was apparently unaffected. He could stand if supported, and after being helped to start could drag himself about, but invariably fell on his right side, sometimes crying out when falling. He ate about an ounce of raw meat and drank a little milk, though evidently his mouth caused him some pain, as he was now freely salivated. I therefore discontinued the mercury and prescribed pot. iodide, to be given three times daily.

On the sixth day there was slight improvement, but all appetite had disappeared. The dog appeared to wish to be left alone, and would drag himself to a corner under some piece of furniture. $\mathrm{He}$ seemed very depressed and dull, but was certainly in less pain.

On the seventh day he was decidedly worse. He could scarcely move from his basket and seemed very dull and listless, except when touched, when he would scream piteously. His hind legs and his tail were hanging limp, almost as if there had been a fracture. $\mathrm{He}$ had quite regained the use of his fore leg, and if put on the ground and frightened, by a great effort he could scramble along out of reach, a]ways, however, tumbling over on his right side and recovering him- 
self only to fall once more. An exaggerated knee jerk was easily obtained. The pupils were normal, the head and neck not so sensitive, but the torticollis well marked. There was an extremely sensitive area along the dorsal spine, extending from the eighth dorsal vertebra to the third lumbar. Also there was pain on passive movement of the tail. As the potass. iodide seemed to be too great a depressant, I prescribed instead liq. hydrarg. et arsenii iodidi (Donovan's solution).

On the eighth and ninth days there was marked improvement. Pain was less in the dorsal spine but still acute in the lumbar region. There was more power in the hind legs, but though he could support himself there was no incoordination of the muscles, so that in slowly walking across the room he would keep his head pointing in the direction he wished to go, while his hind legs carried him continually to the right. Instead therefore of moving in a straight line he moved towards the right in an ever narrowing circle, with his head always pointing to the centre. Any handling of his tail caused great pain. Condition of head and neck unchanged.

Tenth and eleventh days. Continued improvement. The patient was now able to run about, still deviating to the right but to a much less degree. The head and neck were carried more in the normal position, the back level instead of arched, and the legs supporting the body more adequately, though the body still swayed from side to side when standing. The tail could be moved slightly from side to side voluntarily, but hung limp, and apparently could not be raised ; it was stained with fæcal matter. The appetite was maintained, and 3 ozs. of raw meat and a little sago pudding had been taken readily. Though no great pain was present, the little animal showed great disinclination to be handled, but did not mind the sound of the piano or the canary. He was content to lie (always on the right side) in his basket, sometimes sleeping, and sometimes watching all that went on around him.

A week later the dog was apparently well and no pain nor excess of sensitiveness was evident. He-could run about well, though his gait was not perfect, there being still a tendency to move towards the right side, and his tail was not carried properly.

A fortnight later the dog had regained his normal condition of health and was putting on flesh rapidly. No further treatment was advised except good food and regular light exercise.

\section{CASES OF TUBERCULOSIS AMONG DAIRY COWS.}

By W. L. LitTle, M.R.C.V.S., Great Yarmouth.

DURING the last three years I have, from time to time, attended professionally the cows of a large dairy, and been very much surprised at the large number of cases of tuberculosis found there, many of them being very advanced and of great clinical and pathological interest. So great has been the loss to the owner that he has resolved to sell out.

Besides cases of tuberculous pleurisy, pneumonia, and mastitis, 